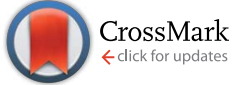

Cite this: RSC Adv., 2016, 6, 12819

Received 26th November 2015 Accepted 17th January 2016

DOI: 10.1039/c5ra25170b

www.rsc.org/advances

\title{
Solvent and branching effect on the two-photon absorption properties of push-pull triphenylamine derivatives
}

\author{
D. Cvejn, ${ }^{a}$ E. Michail, ${ }^{b}$ K. Seintis, ${ }^{b}$ M. Klikar, ${ }^{a}$ O. Pytela, ${ }^{a}$ T. Mikysek, ${ }^{c}$ N. Almonasy, ${ }^{a}$ \\ M. Ludwig, ${ }^{a}$ V. Giannetas, ${ }^{b}$ M. Fakis ${ }^{\star b}$ and F. Bureš*a
}

\begin{abstract}
The photophysical and two-photon absorption (2PA) properties of two tri-podal molecules and of their quadrupolar and dipolar counterparts are reported for a series of solvents with varying polarity. The molecules possess a tri-phenylamine electron donating group and mono-cyano acceptors while olefinic and acetylenic $\pi$-linkers have been used. Branching led to an increase of the molar extinction coefficient and to a slight bathochromic shift of the absorption spectra while the fluorescence quantum yields decrease but they are maintained to relatively high values. Solvatochromic measurements in the tripodal molecules revealed an emitting state with a polar nature. The 2PA cross sections in general increase upon branching but the observed behaviour strongly depends on the type of solvent. The highest 2PA cross sections are obtained in solvents of medium polarity and values as high as 1420 GM are reported.
\end{abstract}

\section{Introduction}

Two-photon absorption (2PA), a nonlinear optical phenomenon related to the imaginary part of the third-order nonlinear susceptibility, constitutes the physical origin of numerous applications such as upconverted lasing, ${ }^{\mathbf{1 , 2}}$ two-photon microscopy and imaging, ${ }^{3-5} 3 \mathrm{D}$ microfabrication and 3D optical data storage, ${ }^{6-10}$ optical limiters etc. ${ }^{11,12}$ 2PA is the simultaneous absorption of two photons by a molecule, atom or ion leading to its excitation to a higher state. The absorbed photons lay typically in the near infrared spectral region (ideally from 700 to $900 \mathrm{~nm}$ i.e. the spectral region of Ti:sapphire fs lasers) and their energy is half the energy between the ground and the final excited state. Compared to one-photon absorption (1PA) in the UV-blue spectral region, using near infrared light in 2PA, is advantageous because of the reduced scattering leading to an increased penetration depth. Besides, 2PA is a process with an intrinsic spatial confinement because of its quadratic dependence on the excitation power. This renders 2PA a great tool for initiating photo-physical or photo-chemical phenomena with a $3 \mathrm{D}$ resolution of the order of $100 \mathrm{~nm} .^{13,14}$

\footnotetext{
${ }^{a}$ Institute of Organic Chemistry and Technology, Faculty of Chemical Technology, University of Pardubice, Studentsk8 573, Pardubice, 532 10, Czech Republic; Web: http://bures.upce.cz. E-mail: filip.bures@upce.cz; Fax: +420 46603 7068; Tel: +420 466037099

${ }^{b}$ Department of Physics, University of Patras, GR-26504, Patras, Greece; Web: http:// www.laserlab.physics.upatras.gr/laserlab/index.php/faculty.html. E-mail: fakis@ upatras.gr; Fax: +30 2610 997470; Tel: +30 2610996794

'Department of Analytical Chemistry, Faculty of Chemical Technology, University of Pardubice, Studentská 573, Pardubice, 53210, Czech Republic
}

The large number of applications that are based on 2PA require the use of suitable materials with enhanced 2PA properties at specific wavelengths accompanied, in certain cases, by a high fluorescence quantum yield. Therefore, the quest for organic molecules satisfying the criteria needed for 2PA based applications has received tremendous attention. It is nowadays well established that organic molecules with increased electron delocalization featuring intramolecular charge transfer (ICT) are the most attractive candidates while their properties can be systematically tuned. ${ }^{15-17}$ These molecules bear electron donating and accepting units adopting a dipolar, quadrupolar, octupolar or multipolar nature. Using octupolar and multipolar compounds i.e. incorporating three or more chromophoric units in a single multichromophoric molecule has been found in most cases to increase their 2PA cross section through the synergetic co-operation of the chromophores. ${ }^{18-27}$ In octupolar or multipolar compounds, co-operation of branches is realized through coherent and/or incoherent coupling among the chromophoric units, the nature of the coupling being dependent on the type of the core and the chemical structure of the branches. However, some requirements such as stability, solubility and cell permeability are dependent on the size of the molecules. This leads to the need for obtaining the best 2PA properties within a small molecular volume.

In the past, several works have reported on a comparative study of the multi-chromophoric systems with their model chromophores. These studies, both theoretical and experimental, have attempted to shed light on why multichromophoric systems exhibit improved 2PA activity compared to model compounds and why some times 2PA activity is 
reduced. ${ }^{\mathbf{2 0 , 2 3 , 2 4 , 2 8 - 3 3}}$ However, several issues remain not well understood, because of the complexity of multi-chromophoric systems, such as the exact effect of the core, the localization (or not) of the excited state on a single chromophore (branch), the effect of solvent etc. Localization of the excited state on a single branch may hinder significant branch co-operation and enhancement of the 2PA properties. On the other hand, the proximity of chromophores allow branch incoherent co-operation by means of through space interactions such as energy hopping. The solvent is of great importance because due to the polar nature of the chromophores used, large charge displacements take place upon one- or two-photon excitation, while the magnitude and nature of chromophore coupling can be tuned by changing the solvent polarity. Therefore, 2PA molecules are very sensitive on the polarity of the environment which influences both their linear and nonlinear optical properties. In the past, it has been found that large 2PA cross sections, $\delta_{2 \mathrm{PA}}$, are achieved in medium polar solvents where usually a relatively high fluorescence quantum yield is also exhibited..$^{34-36}$

In our very recent work, we have studied the $2 \mathrm{PA}$ properties of a large series of tri-podal molecules based on a central triphenylamine (TPA) electron donor and various peripheral cyano-based acceptors. ${ }^{37}$ It has been found that two tripodal molecules with mono-cyano acceptors and acetylenic or olefinic $\pi$-conjugated bridges exhibited the largest 2PA cross section. In this respect and as an extension of our recent work, we report herein a comparative study of two tripodal molecules (T) with their quadrupolar (Q) and dipolar/linear (L) analogues. The synthesis of the quadrupolar and dipolar compounds is described and the effect of branching on thermal, electrochemical, photophysical and 2PA properties is studied. Finally, solvent effects on linear and non-linear optical properties are described. The experimental outcomes are further supported by DFT calculations.

\section{Results and discussion}

\section{Synthesis}

In general, the synthesis of target chromophores 1-2 consists of two steps (Scheme 1). The first step involves preparation of properly halogenated triphenylamine, while the subsequent one comprises of one-, two- or threefold Sonogashira and Suzuki-Miyaura cross-coupling reactions. Commercially available triphenylamine was iodinated in two different ways. The well-established threefold iodination of TPA (3) using the $\mathrm{HgO} /$ $\mathrm{I}_{2}$ system afforded tris(4-iodophenyl)amine 6 in $88 \%$ yield. ${ }^{38}$ However, the iodination using $\mathrm{HgO}$ as a Lewis acid lacks selectivity towards mono- and bisiodinated products $\mathbf{4}$ and $\mathbf{5}$. Hence, the iodination was carried out using $\mathrm{AgNO}_{3} / \mathrm{I}_{2} / \mathrm{EtOH}$ system, which was formerly used for iodination of carbazole. ${ }^{39}$ In this way, the desired mono- and bisiodinated triphenylamines 4 and 5 were prepared in reasonable yields of 51 and $77 \%$. The final one-, two- and threefold Sonogashira and Suzuki-Miyaura cross-coupling reactions were carried out under standard condition used for the construction of tripodal molecules $\mathbf{1 T}$ and $2 \mathbf{T}^{37}$ The linear and quadrupolar molecules
1L, 1Q and 2L, 2Q were prepared in good yields as shown in Scheme 1 . The attained yields decrease slightly with increasing the multiplicity of the cross-coupling.

\section{Thermal properties}

Thermal behaviour of target chromophores 1L, 1Q, 1T and $2 \mathrm{~L}$, 2Q, 2T was studied by differential scanning calorimetry (DSC). The measured melting temperatures $\left(T_{\mathrm{m}}\right)$ and temperatures of thermal decomposition $\left(T_{\mathrm{d}}\right)$ are listed in Table 1. Fig. 1 shows two representative spectra of $\mathbf{1 L}$ and $\mathbf{1 Q}$. Both these compounds showed sharp melting points at 101 and $232{ }^{\circ} \mathrm{C}$, which is for $1 \mathrm{Q}$ immediately followed by decomposition. In contrast to this, compounds 1T, 2L and 2Q showed wide peaks corresponding to their melting points at 217,131 and $203{ }^{\circ} \mathrm{C}$ and surprisingly no decomposition peaks. However, a slow decrease of the heat flow was observed and the samples were clearly carbonized after heating up to $400{ }^{\circ} \mathrm{C}$. Compounds $\mathbf{1 T}$ and $2 \mathrm{Q}$ showed a wide enantiotropic solid-solid transition at $37-82$ and $150-190{ }^{\circ} \mathrm{C}$. As a main feature, the branching of chromophores increases their melting temperatures (except 1T), but the decomposition remained unresolved. However, chromophore 2T resisted thermal decomposition up to $477^{\circ} \mathrm{C}$. Chromophores in series 1 bearing acetylenic $\pi$-linkers proved to be generally less thermally stable than the corresponding olefins in series 2 .

\section{Electrochemistry}

Electrochemical studies of 1L, 1Q, 1T and 2L, 2Q, 2T were carried out by cyclic voltammetry (CV), rotating disc voltammetry (RDV) and polarography. All measurements were carried out in acetonitrile containing $0.1 \mathrm{M} \mathrm{Bu}_{4} \mathrm{NPF}_{6}$ as electrolyte. The acquired first oxidation and reduction potentials are summarized in Table 1 . As a main feature, they showed only negligible changes upon branching. When going from 1L to 1Q and 1T, the first oxidation potential is slightly shifted to more positive values $\left(\Delta E_{1 / 2 \text { (ox } 1)}=0.06 \mathrm{~V}\right)$. Considering the central amino donor as a main oxidation centre, this observation reflects its lowered electron density caused by attaching more electron acceptors (enhanced/spread ICT). The first oxidation potentials of $2 \mathbf{L}, 2 \mathbf{Q}$ and $2 \mathbf{T}$ are almost identical. The first reductions within both series 1 and 2 became slightly facilitated ( $E_{1 / 2(\operatorname{red} 1)}$ are shifted to more positive values) upon branching, which implies that attaching more electron acceptors to one electron donor results in their competition in the ICT. The nature of the $\pi$-linker showed much more significant effect. When comparing series 1 and 2, the latter showed significantly lower first oxidation potentials and thus also narrowed HOMO-LUMO gap $(\Delta E=2.86-2.89$ vs. $2.65-2.70 \mathrm{~V})$. This is in accordance with our observations on enhanced D-A interaction across olefinic than acetylenic $\pi$-linkers. ${ }^{\mathbf{4 1}}$

\section{Steady state absorption and fluorescence properties}

The optical properties of all target compounds were investigated by electronic absorption and emission spectra in various solvents. Fig. 2 shows the absorption and fluorescence spectra in THF; the principal photophysical parameters are given in Table 1. 


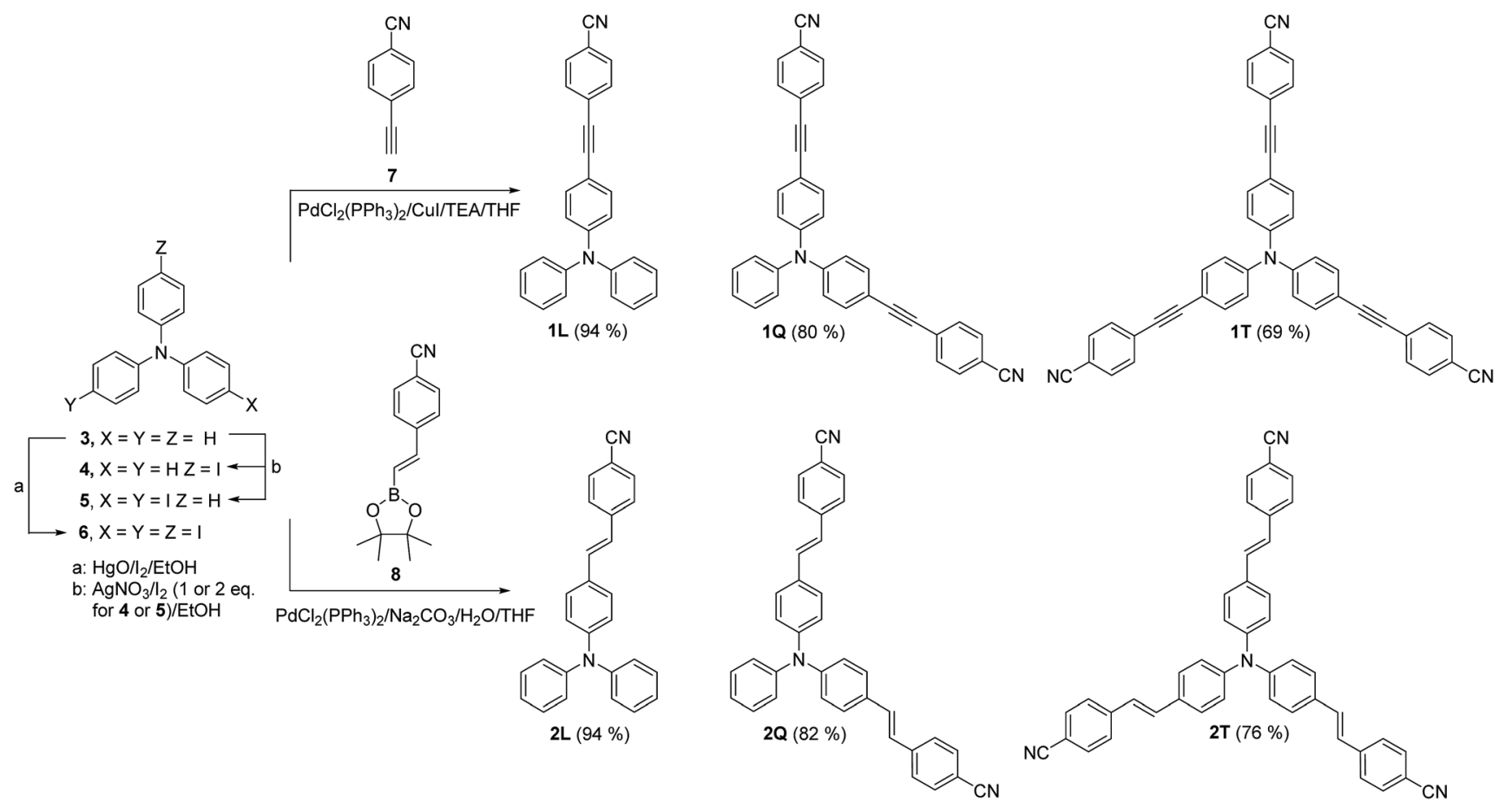

Scheme 1 Synthetic pathway leading to target linear, quadrupolar and tripodal chromophores.

Compared to all chromophores in series $\mathbf{1}$, molecules $2 \mathbf{L}, \mathbf{2 Q}$ and $2 \mathrm{~T}$ showed bathochromically shifted longest-wavelength absorption maxima $\left(\Delta \lambda_{\max }^{\mathrm{A}}=14-24 \mathrm{~nm}\right)$, which reflects more efficient ICT over olefinic than acetylenic $\pi$-linkers as seen by electrochemistry (see above). Besides, when going from linear (L) to quadrupolar (Q) chromophores, the absorption spectra are red-shifted as a result of attaching more electron acceptors/ branches and indicate an electronic coupling between the branches. ${ }^{21,23,31}$

In addition, when going from quadrupolar (Q) to tri-podal (T), the absorption spectra are slightly blue-shifted implying that attaching a third cyano-substituted branch on the central amino donor has a diminished effect on the absorption properties. This blue shift is more significant for $\mathbf{2 T}$ in THF, where specific solvent-solute interactions should play a role because in other solvents the absorption peak of $2 \mathrm{~T}$ is found at $411-413$ $\mathrm{nm}$ (Table 2) i.e. close to that of 2Q. In the absorption spectra of the quadrupolar compounds $1 \mathbf{Q}$ and $\mathbf{2 Q}$, apart from the main peak, a shoulder located at the high-energy side of the peak, is also observed pointing to a splitting of the absorption bands. This splitting results from the coupling between branches in the case of $1 \mathrm{Q}$ and $2 \mathrm{Q}$ and it is explained by the Frenkel exciton model, which is also applied to $\mathrm{H}^{-}$and $\mathrm{J}$-aggregates and assumes electrostatic interaction of the chromophores. ${ }^{20,32,42-44}$ The model predicts that in the quadrupolar V-shaped molecules, the singlet excited state splits into two bands which are positioned themselves symmetrically with respect to the excited state of the linear molecule. Both states are one photon allowed while the lower energy one has stronger oscillator strength. On the other hand, the excited state of tripodal compounds (1T and 2T) is split into three states. The two states are degenerate and lay at the low-energy side of the linear chromophore's excited

Table 1 Summarized properties of target chromophores

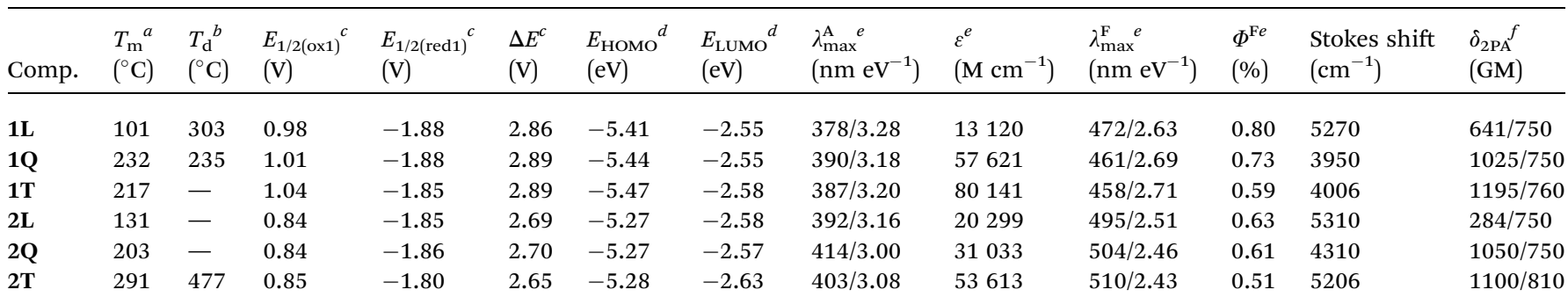

${ }^{a} T_{\mathrm{m}}=$ melting point (the point of intersection of a baseline before the thermal effect with a tangent). ${ }^{b} T_{\mathrm{d}}=$ thermal decomposition (pyrolysis in $\mathrm{a} \mathrm{N}_{2}$ atmosphere). ${ }^{c} E_{1 / 2(\mathrm{ox} 1)}$ and $E_{1 / 2(\text { red } 1)}$ are half-wave potentials of the first oxidation and reduction, respectively; all potentials are given $v s$. SCE; $\Delta E$ $=E_{1 / 2(\mathrm{ox} 1)}-E_{1 / 2(\mathrm{red} 1)} \cdot{ }^{d}-E_{\mathrm{HOMO} / \mathrm{LUMO}}=E_{1 / 2(\mathrm{ox} 1 / \mathrm{red} 1)}+4.429$ (ref. 40$) .{ }^{e}$ Measured in THF. ${ }^{f}$ The wavelength of the maximum $2 \mathrm{PA}$ cross section is shown after slash (measured in THF). 


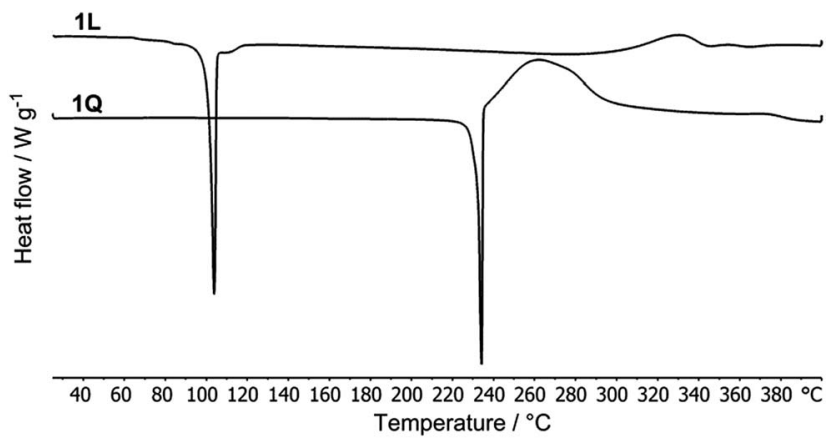

Fig. 1 Representative DSC curves of chromophores $1 \mathrm{~L}$ and $1 Q$ determined with a scanning rate of $3^{\circ} \mathrm{C} \mathrm{min}{ }^{-1}$ under $\mathrm{N}_{2}$.

state while the third state is located at the high-energy side and is predicted to have zero oscillator strength for 1PA. This explains why the spectra of tripodal compounds $\mathbf{1 T}$ and $\mathbf{2 T}$ exhibit a single peak without any shoulder and/or broadening. As expected, the molar extinction coefficient of the chromophores increases upon branching. In series $\mathbf{1}$, though, the increase is not linear to the number of branches indicating a strong coupling. In series $\mathbf{2}$, the value of extinction coefficient is approximately proportional to the number of branches indicating a nearly independent behaviour of chromophores. ${ }^{23,31,45}$

Regarding the fluorescence spectra, 1Q and 1T exhibit a hypsochromically shifted spectrum compared to that of $\mathbf{1 L}$ attributed to a less polar excited state. In series 2, on the other hand, a red-shifted fluorescence is observed for $2 \mathbf{Q}$ and $2 \mathbf{T} v s$. $2 \mathbf{L}$ meaning that the excited state in the branched compounds is more polar and more stabilized. In both cases, the observed differences in the fluorescence spectra indicate a coupling between branches. The fluorescence quantum yields, $\Phi^{\mathrm{F}}$, in series $\mathbf{2}$ are lower than in series $\mathbf{1}$ perhaps due to the more efficient ICT formation (Table 1). In both series, $\Phi^{\mathrm{F}}$ decreases upon branching, implying increased non-radiative pathways, but is maintained to relatively high values similar to those found for other TPA-based tri-podal molecules. ${ }^{21,30,31}$ It is worth

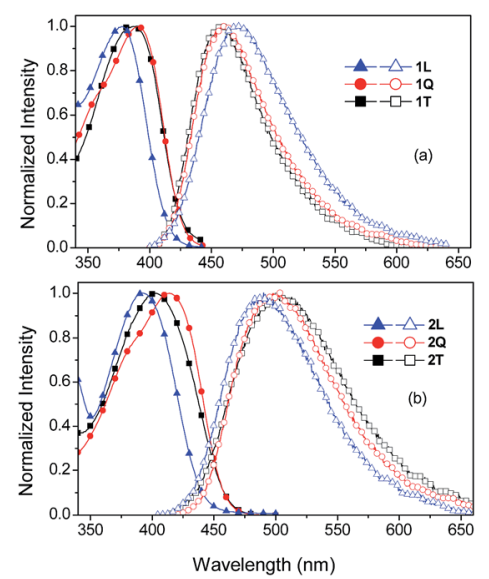

Fig. 2 Steady state absorption (full points) and fluorescence spectra (empty points) of chromophores in series 1 (a) and 2 (b) in THF.
Table 2 Photophysical parameters of $1 \mathrm{~T}$ and $2 \mathrm{~T}$ in various solvents

\begin{tabular}{llllll}
\hline Comp. & Solvent & $\begin{array}{l}\lambda_{\max }^{\mathrm{A}} \\
\left(\mathrm{nm} \mathrm{eV}^{-1}\right)\end{array}$ & $\begin{array}{l}\lambda_{\max }^{\mathrm{F}} \\
\left(\mathrm{nm} \mathrm{eV}^{-1}\right)\end{array}$ & $\begin{array}{l}\text { Stokes shift } \\
\left(\mathrm{cm}^{-1}\right)\end{array}$ & $\Phi^{\mathrm{F}}(\%)$ \\
\hline \multirow{2}{*}{$\mathbf{T}$} & & & & & \\
& Toluene & 392 & 428 & 2146 & 0.52 \\
& THF & 387 & 458 & 4006 & 0.59 \\
& Acetone & 387 & 482 & 5093 & 0.37 \\
& Acetonitrile & 387 & 505 & 6038 & 0.35 \\
& Toluene & 413 & 464 & 2661 & 0.54 \\
& THF & 403 & 510 & 5206 & 0.51 \\
& Acetone & 411 & 550 & 6083 & 0.37 \\
& Acetonitrile & 411 & 564 & 6569 & 0.28
\end{tabular}

noting that $\Phi^{\mathrm{F}}$ for the tri-podal molecules remains relatively high even in solvents of high polarity such as acetone and acetonitrile (Table 2).

Fig. 3 shows the absorption and fluorescence spectra of tripodal chromophores $\mathbf{1 T}$ and $2 \mathrm{~T}$ in toluene (TOL), THF, acetone (ACT) and acetonitrile (ACN); the measured photophysical data are given in Table 2 . The increased solvent polarity has only diminished effect on the absorption spectra. On the other hand, the fluorescence spectra exhibit a positive solvatochromism (i.e. a bathochromic shift with $\Delta \lambda_{\max }^{\mathrm{F}}=77 / 99 \mathrm{~nm}$ upon increasing the solvent polarity). The spectra in solvents of low polarity (toluene) are narrow with a weak shoulder (more obvious in the spectra of 2T), while they become featureless and broad in high polarity solvents.

The red shift and broadening of the fluorescence spectra with increasing solvent polarity resembles the behaviour observed in linear $\mathrm{D}-\pi-\mathrm{A}$ compounds and indicates that the emission originates from an excited state with polar nature i.e. that the main emitting chromophoric unit is the single branch. ${ }^{23,32}$ The Lippert-Mataga plots ${ }^{46,47}$ for $1 \mathrm{~T}$ and $2 \mathrm{~T}$ in Fig. 4 show that the Stokes shift increases linearly with the solvent polarizability $(\Delta f)$ indicating a stabilization of the excited state in polar solvents; the correlation between the Stokes shift and the solvent polarizability is especially tight for $\mathbf{2 T}$. The slope of
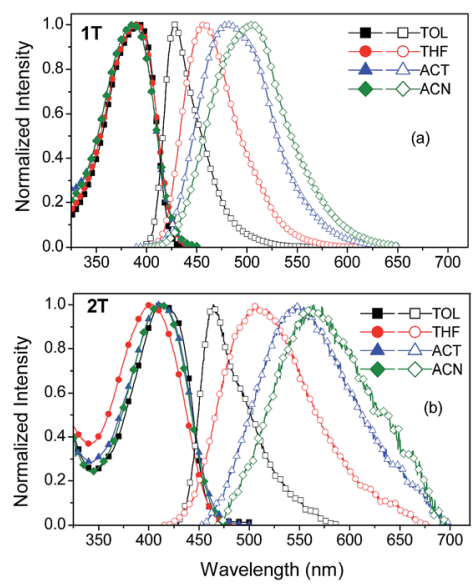

Fig. 3 Steady state absorption (full points) and fluorescence spectra (empty points) of chromophores $1 \mathrm{~T}$ (a) and $2 \mathrm{~T}$ (b) in toluene, THF, acetone and acetonitrile. 


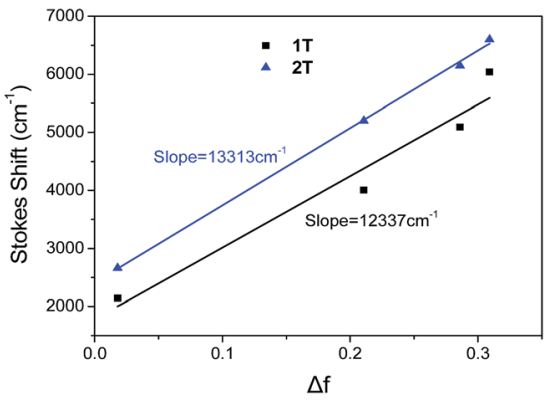

Fig. 4 Lippert-Mataga plots for chromophores 1T and 2T.

this diagram depends on the difference between the excited and ground state dipole moments and the radius of the molecular cavity ${ }^{46,47}$ Considering small structural changes between $1 \mathrm{~T}$ and 2T (olefinic $v s$. acetylenic $\pi$-linkers), we can assume that the radius of the cavity is similar for both molecules. The DFTcalculated box or molar volumes of $\mathbf{1 T / 2 T}$ equal to $2.35 \times$ $10^{4} / 2.57 \times 10^{4} \mathrm{~A}^{3}$ or $542.5 / 552.1 \mathrm{~cm}^{3} \mathrm{~mol}^{-1}$, respectively, which further confirms their close spatial arrangement. Hence, the slope is a quantitative measure of the polar nature of the excited state. Higher slope is obtained for $\mathbf{2 T}$, which indicates its larger dipole moment change relative to $\mathbf{1 T}$ and suggests a more polar excited state of $\mathbf{2 T}$.

This is corroborated by the frontier molecular orbitals of 1T and $2 \mathbf{T}$, reported in a previous work of ours, ${ }^{37}$ where it was shown that the LUMO level of $2 \mathrm{~T}$ is located on a single dipolar branch while that of $\mathbf{1 T}$ is located on a single branch but also has a small contribution on a second branch, rendering the excited state less polar.

\section{PA properties}

Fig. 5 and 6 show the $2 \mathrm{PA}$ spectra of $1 \mathrm{~L}, 1 \mathrm{Q}$ and $1 \mathrm{~T}$ and of $2 \mathrm{~L}, 2 \mathrm{Q}$ and $2 \mathrm{~T}$ respectively in various solvents. In compounds $1 \mathrm{~L}, \mathbf{1 Q}$ and $1 \mathrm{~T}$ the maximum 2PA cross section is observed at the short wavelength region of our excitation range while in $2 \mathbf{L}, \mathbf{2 Q}$ and 2T, the 2PA peaks are observed at short to medium wavelengths across our scanning spectral window which is in agreement with the shift in the 1PA spectra. Interestingly, 1L exhibits a maximum $2 \mathrm{PA}$ cross section (800 GM) in the low polarity solvent toluene. However, toluene is not the optimum choice upon increasing the number of branches since both $1 \mathrm{Q}$ and $\mathbf{1 T}$ exhibit large values of $2 \mathrm{PA}$ cross sections in the more polar solvents THF and acetone. Specifically, 1T has a 2PA cross section of $1400 \mathrm{GM}$ in acetone which is almost twice larger than the value found for $\mathbf{1 T}$ in toluene. In addition, $2 \mathrm{~L}, \mathbf{2 Q}$ and $\mathbf{2 T}$ exhibit the maximum 2PA cross sections in acetone and THF while the largest $2 \mathrm{PA}$ cross section is observed for $2 \mathbf{Q}$ in acetone (1420 GM). The above findings are in agreement with our previous works where we have studied the 2PA properties of linear quadrupolar molecules and have found their maximum 2PA cross section values in solvents of medium polarity. ${ }^{36,48}$ These results are also in agreement with other experimental and theoretical works by Woo et al. Orłowski et al. Wang et al. and Luo et al. in which a general conclusion was that enhanced 2PA
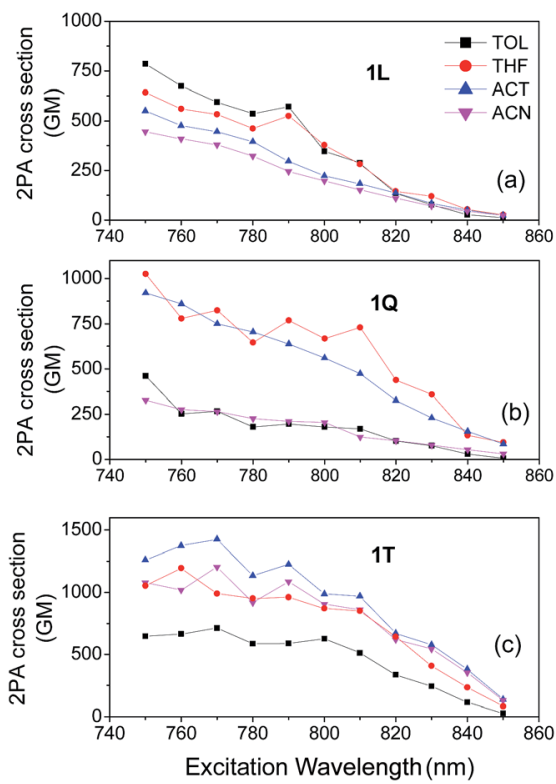

Fig. $52 \mathrm{PA}$ spectra of (a) $1 \mathrm{~L}$, (b) $1 \mathrm{Q}$ and (c) $1 \mathrm{~T}$ in various solvents.

efficiency is expected in solvents of medium polarity where intramolecular charge transfer process takes place and excited states posses a highly polar nature. ${ }^{34,35,49,50}$ However, it is unclear why $1 \mathrm{~L}$ exhibits enhanced $2 \mathrm{PA}$ properties in toluene and its $2 \mathrm{PA}$ efficiency decreases monotonically as the solvent polarity increases. Maybe this is due to specific solvent-solute interactions in polar solvents redistributing the energetics of the excited state and changing the excitation transition dipole moments.

Next, in order to better evaluate the effect of branching and to assess whether the observed behaviour of branched compounds is due to a cooperative or additive effect, we
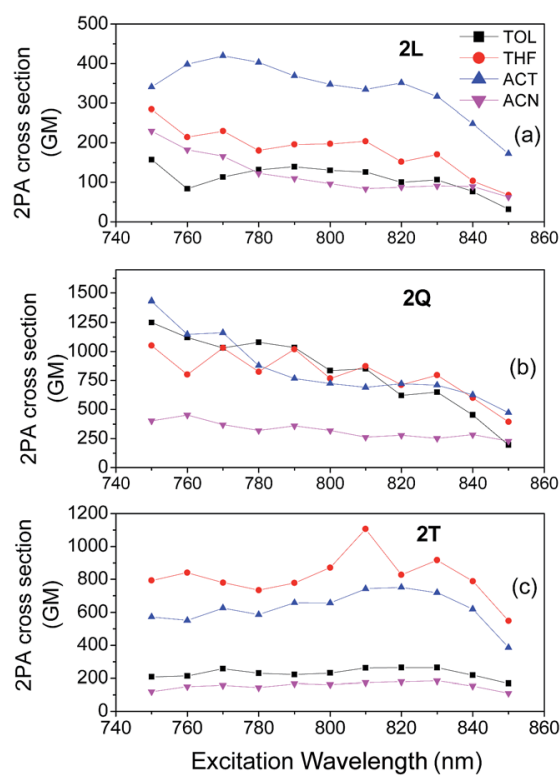

Fig. 6 2PA spectra of (a) 2L, (b) $2 \mathrm{Q}$ and (c) $2 \mathrm{~T}$ in various solvents. 
compare in series 1 and 2, the 2PA cross sections normalized per branch number. ${ }^{23,31}$ This comparison led to varied results depending on the series and solvent.

In series $\mathbf{1}$, the $2 \mathrm{PA}$ cross sections/branch values decrease or remain approximately constant in quadrupolar and octupolar compounds compared to dipolar one. The most significant decrease in series $\mathbf{1}$ was observed in toluene where the cross section/branch value of $800 \mathrm{GM}$ in 1L decreases to approximately 200 GM for 1Q and 1T. Similarly, in acetonitrile a decrease of the normalized 2PA cross sections is also observed while, in THF and acetone, a nearly additive behaviour is exhibited meaning that the 2PA cross sections/branch are almost the same in 1L, 1Q and 1T. Interestingly, in series 2, 2Q compared to $2 \mathbf{L}$, exhibits $2 \mathrm{PA}$ cross section/branch values that are above the additive behaviour in all solvents except from acetonitrile. This 2PA enhancement is due to a co-operative behaviour of branches and leads to an increase of the 2PA cross section/branch values of approximately $4,1.8$ and 1.7 times in toluene, THF and acetone respectively. Unfortunately, this co-operative enhancement is not observed in $\mathbf{2 T}$ where a decrease of the $2 \mathrm{PA}$ cross sections/branch compared to $2 \mathbf{Q}$ is observed in all solvents. Besides, in 2T, an enhancement of the 2PA spectrum at long wavelengths is observed compared to $2 \mathbf{L}$ and $2 \mathbf{Q}$, which probably may be due to breaking of symmetry.

In the past, several works have reported on the enhancement of 2PA in branched compounds, that is more than the additive limit, due to the increase in dimensionality, delocalization and co-operation of chromophores. ${ }^{31,51-53}$ Goodson and co-workers have associated such a co-operative enhancement in branched compounds with an ultrafast depolarization of emission. ${ }^{38}$ However, in other works, an additive behaviour or even decrease of 2PA efficiency i.e. of the 2PA cross section/branch value was also reported. ${ }^{19,27,32,33,54}$ The understanding of why branching is not always the optimum design strategy remains a puzzling issue. It is mentioned, though, that the above comparison of the branched compounds $v s$. the linear ones should be made over a wide wavelength range. Katan et al. have shown that a tripodal compound with dipolar branches showed only a slight enhancement of its 2PA cross section close to $800 \mathrm{~nm}$ compared to its linear counterpart, while a significant enhancement was observed at the higher energy region, close to $700 \mathrm{~nm} .^{31}$ Makarov et al. have reported that in their tripodal compounds, the 2PA spectrum is strongly shifted to high energies compared to the linear molecules i.e. the 2PA cross sections decrease in the low-energy side of the spectrum while they are enhanced in

Table 3 DFT calculated properties ${ }^{a}$ of target chromophores

\begin{tabular}{lllll}
\hline Comp. & $E_{\text {Hомо }}{ }^{a}(\mathrm{eV})$ & $E_{\text {LUмо }}{ }^{a}(\mathrm{eV})$ & $\Delta E(\mathrm{eV})$ & $\mu(\mathrm{D})$ \\
\hline 1L & -5.51 & -2.27 & 3.24 & 7.94 \\
1Q & -5.67 & -2.54 & 3.13 & 7.01 \\
1T & -5.80 & -2.67 & 3.13 & 0.001 \\
2L & -5.42 & -2.34 & 3.08 & 7.80 \\
2Q & -5.52 & -2.59 & 2.93 & 7.12 \\
2T & -5.62 & -2.75 & 2.87 & 0.221
\end{tabular}

${ }^{a}$ Calculated at the DFT B3LYP/6-311++G(2d,p) level. the high energy one. ${ }^{19}$ Therefore, in our case, although a 2PA enhancement that is above the additive limit is observed for $\mathbf{2 Q}$, the fact that $2 \mathrm{~T}$ does not exhibit a similar behaviour may be due to the limited spectral window of our experimental system.

Finally, another feature that warrants discussion is the comparison of the 1PA and 2PA spectra at half wavelengths. In dipolar molecules, the same excited state is populated both under 1PA and 2PA, so a similarity of 1PA and 2PA spectra is observed. In V-shaped molecules the 2PA are blue shifted compared to the 1PA ones. ${ }^{19}$ In the case of octupolar molecules, the excitonic model predicts that 1PA is expected mainly to the two lowest degenerate excited states while 2PA to the higher energy excited state. However, previous works have shown a similarity of 1PA and 2PA spectra ${ }^{21,23}$ while a shift between these spectra has also been reported. ${ }^{31}$ In the compounds studied herein, 1T exhibits the peak of the 2PA spectra at 760$770 \mathrm{~nm}$ and $2 \mathrm{~T}$ at $810-830 \mathrm{~nm}$ in all solvents. Both these regions are at twice the peak wavelengths of 1PA spectra of 1T and 2T (Table 2). This good similarity of the 1PA and 2PA spectra at half wavelengths is an indication of weak coupling among branches.

\section{Quantum chemical calculations}

The spatial and electronic properties of chromophores in both series 1 and $\mathbf{2}$ were investigated using the Gaussian W09 package $^{55}$ at the DFT level. The initial geometries of molecules were estimated using the PM3 method implemented in Argus$\mathrm{Lab}^{\mathbf{5 0 , 5 6}}$ and these were subsequently optimized using the DFT B3LYP/6-311++G(2d,p) method. The energies of the HOMO and LUMO, their differences and ground state dipole moments were calculated with the DFT B3LYP/6-311++G(2d,p) and are summarized in Table 3. The calculated energies of the HOMO/ LUMO and their differences correlate well with the experimental data obtained by the electrochemical measurements (Table 1). Hence, the used DFT method can be considered as
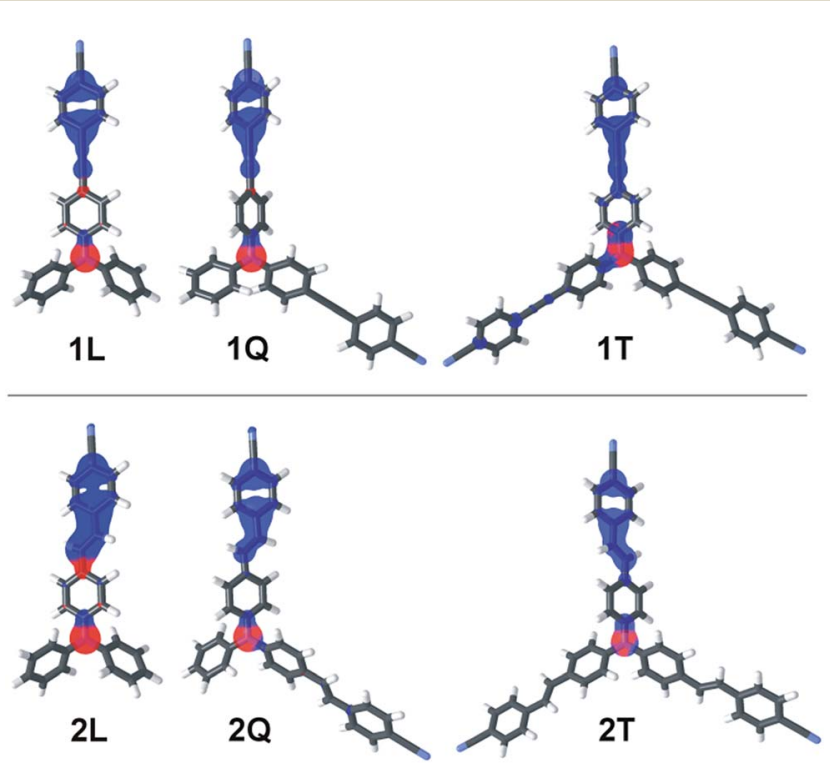

Fig. 7 HOMO (red) and LUMO (blue) visualizations in target chromophores. 
a reasonable tool for the description of trends in electronic properties of chromophores 1-2.

As a main feature, one can observe that the energies of the HOMO and LUMO steadily increase when going from linear to quadrupolar and tripodal molecules. This results in narrowed HOMO-LUMO gap $(\Delta E)$, however the effect of branching seems to be negligible similar to that observed by electrochemical measurements (Table 1). The olefinic units in molecules in series 2 allow higher D-A coupling and, therefore, chromophores $2 \mathbf{L}, \mathbf{2 Q}$ and $2 \mathrm{~T}$ showed reduced HOMO-LUMO gap.

The HOMO and LUMO distributions in all target molecules are shown in Fig. 7. Whereas the HOMO is localized on the central amino donor, the LUMO occupies the peripheral CN acceptor(s) and the adjacent $\pi$-system. The LUMO is predominantly localized over one particular branch and only negligibly over the second branch in $\mathbf{Q}$ and $\mathbf{T}$ series of molecules with the contribution over the second branch being larger in series 1 . The second/third branch in $\mathbf{Q}$ and $\mathbf{T}$ compounds is occupied by LUMO+1. Both frontiers orbitals are clearly separated which further confirms the ICT character of all chromophores. When going from unsymmetrical $\mathbf{L}$ and $\mathbf{Q}$ chromophores to tripodal molecules 1T and 2T, having $D_{3}$ and $C_{3}$ group of symmetry, the calculated ground state dipole moments diminish significantly from about 7-8 to almost $0 \mathrm{D}$ for $\mathbf{1 T}$.

\section{Conclusions}

A study of the effect of solvent polarity and branching strategy on the photophysical and 2PA properties of triphenylamine push-pull molecules was presented. For this reason, the properties of two tripodal molecules were compared with their quadrupolar and dipolar analogues in various solvents. The photophysical properties have shown a dipolar nature of the emitting state in the tripodal molecules, a behaviour resembling that of the linear dipolar molecules. A small coupling among branches was found as a result of a slight red-shift of the absorption spectra of the branched compounds. The investigation of the 2PA properties has shown that the 2PA cross section of the branched compounds increases compared to that of the dipolar ones. In some cases, depending on the solvent used and molecule, this increase is higher than what was expected based on an additive behaviour of the branches, implying a co-operative effect. The highest $2 \mathrm{PA}$ cross section was observed in solvents of medium polarity and a value as high as $1420 \mathrm{GM}$ was reported for the quadrupolar molecule $2 \mathbf{Q}$ in acetone.

\section{Experimental}

\section{General methods}

For the synthesis and characterization of tripodal chromophores 1T and 2T see the literature. ${ }^{37}$ THF was dried in Puresolv ${ }^{\mathrm{TM}}$ micro solvent purification system. All commercial chemicals and solvents were purchased from suppliers such as Sigma Aldrich, Acros and TCI at reagent grade and were used as obtained. All cross-coupling reactions were carried out in flamedried flasks under argon. Thin-layer chromatography (TLC) was conducted on aluminum sheets coated with silica gel 60 F254 with visualization by a UV lamp (254 or $365 \mathrm{~nm}$ ). ${ }^{1} \mathrm{H}$ and ${ }^{13} \mathrm{C}$ NMR spectra were recorded at 400 and $100 \mathrm{MHz}$, respectively, with a Bruker AVANCE 400 instrument, or at 500 and $125 \mathrm{MHz}$, respectively, with Bruker Ascend ${ }^{\mathrm{TM}} 500$. Chemical shifts in ${ }^{1} \mathrm{H}$, ${ }^{13} \mathrm{C}$ spectra are reported in ppm relative to the signal of $\mathrm{Me}_{4} \mathrm{Si}$. The residual solvent signal in the ${ }^{1} \mathrm{H}$ and ${ }^{13} \mathrm{C}$-NMR spectra was used as an internal reference $\left(\mathrm{CDCl}_{3} 7.25\right.$ and $77.23 \mathrm{ppm}$, $\mathrm{CD}_{2} \mathrm{Cl}_{2} 5.32$ and $\left.54.00 \mathrm{ppm}\right)$. Apparent resonance multiplicities are described as s (singlet), d (doublet), and $\mathrm{m}$ (multiplet), apparent coupling constants of multiplets $\left({ }^{3} J\right.$ or $\left.{ }^{4} J\right)$ are given in Hz. IR spectra were recorded as neat using HATR adapter on a Perkin-Elmer FTIR Spectrum BX spectrometer. High resolution MALDI MS spectra were measured on a MALDI mass spectrometer LTQ Orbitrap XL (Thermo Fisher Scientific, Bremen, Germany) equipped with nitrogen UV laser (337 nm, $60 \mathrm{~Hz}$ ). The LTQ Orbitrap instrument was operated in positiveor negative-ion mode over a normal mass range $(\mathrm{m} / \mathrm{z} 50-2000)$ with resolution 100000 at $\mathrm{m} / z=400$. The survey crystal positioning system (survey CPS) was set for the random choice of shot position by automatic crystal recognition. 2,5-Dihydroxybenzoic acid (DHB) was used as a matrix. Mass spectra were averaged over the whole MS record for all measured samples. Thermal properties of target molecules were measured by DSC with a Mettler-Toledo STARe System DSC 2/700 equipped with FRS 6 ceramic sensor and cooling system HUBERT TC100-MT RC 23.

The absorption spectra were measured on a UV/vis PerkinElmer Lambda 35 spectrophotometer at room temperature. The steady-state fluorescence spectra were measured using a Perkin-Elmer LS 55 spectrophotometer. The spectra were recorded by setting the excitation wavelength at the absorption maxima of the measured compounds. The instrument provides corrected excitation spectra directly; the fluorescence spectra were corrected for the characteristics of the emission monochromator and for the photomultiplier response. For fluorescence measurements, the solutions of very low concentration about $10^{-6} \mathrm{~mol} \mathrm{~L}^{-1}$ (optical density $\sim 0.05$ at the excitation wavelength in $1 \mathrm{~cm}$ cell) were used; the following fluorescence standards were used for the determination of the fluorescence quantum yields: quinine sulphate in $0.5 \mathrm{M}$ aqueous $\mathrm{H}_{2} \mathrm{SO}_{4}$ $\left(\lambda_{\max }^{\mathrm{F}}=445 \mathrm{~nm}, \Phi^{\mathrm{F}}=0.546\right)^{57}$ and coumarin 153 in ethanol $\left(\lambda_{\max }^{\mathrm{F}}=536 \mathrm{~nm}, \Phi^{\mathrm{F}}=0.38\right) . .^{58}$

The two-photon absorption properties of the dyes were studied by means of a two-photon excited fluorescence (TPEF) technique. ${ }^{21,59-61}$ A mode-locked Ti:sapphire laser emitting $80 \mathrm{fs}$ pulses tunable from 750 to $850 \mathrm{~nm}$ was used as the excitation source. The laser beam was focused on the samples by a $0.32 \mathrm{NA}$ objective lens while the 2PA induced fluorescence was collected backward by the same objective lens. It was then separated from the excitation beam by using a dichroic mirror and a series of short-pass filters. A photomultiplier connected to photoncounting electronics was used to detect the emitted fluorescence. The detected fluorescence intensity was in all cases proportional to the square of the excitation power verifying that the observed fluorescence was due to two-photon absorption. The samples were $10^{-4} \mathrm{M}$ solutions of the chromophores in 
various solvents. Finally, the $2 \mathrm{PA}$ cross sections, $\delta_{\mathrm{TPA}}$, were determined by using Rhodamine $\mathrm{B}\left(10^{-4} \mathrm{M}\right.$ in $\left.\mathrm{MeOH}\right)$ as reference.

\section{General method for the synthesis of $1 \mathrm{~L}$ and $1 \mathrm{Q}$}

Iodinated triphenylamine derivatives 4 or $5(0.23 \mathrm{mmol})$ and 4-ethynylbenzonitrile ( 0.3 or $0.6 \mathrm{mmol})$ were dissolved in dry THF (15 ml) and TEA (5 ml, $36 \mathrm{mmol})$. Argon was bubbled through the mixture for $10 \mathrm{~min}$, whereupon $\mathrm{PdCl}_{2}\left(\mathrm{PPh}_{3}\right)_{2}$ (16 mg, $0.023 \mathrm{mmol}$ ) and CuI (13 $\mathrm{mg}, 0.069 \mathrm{mmol}$ ) were added and the reaction was heated to $70{ }^{\circ} \mathrm{C}$ for $8 \mathrm{~h}$. The reaction mixture was poured into the sat. solution of $\mathrm{NH}_{4} \mathrm{Cl}(100 \mathrm{ml})$ and was extracted with DCM $(3 \times 100 \mathrm{ml})$. The combined organic extracts were dried over anhydrous $\mathrm{Na}_{2} \mathrm{SO}_{4}$ and concentrated in vacuo. The crude product was purified by column chromatography $\left(\mathrm{SiO}_{2}\right.$, hexane/EtOAc $\left.4: 1\right)$.

Chromophore 1L. Title compound was synthesized from 4 (85 mg) following the general method. Pale yellow solid. Yield (80 mg, 94\%). $R_{\mathrm{f}} 0.7\left(\mathrm{SiO}_{2}\right.$; EtOAc/hexane $\left.1: 4\right) . \mathrm{Mp} 101{ }^{\circ} \mathrm{C}$ (lit. ${ }^{62}$ $159^{\circ} \mathrm{C}$ ). IR (HATR) $\nu_{\max } / \mathrm{cm}^{-1} 3030,2212(\mathrm{CN}), 1578,1486,1266$, 1176, 1073, 755, 694; ${ }^{1} \mathrm{H}-\mathrm{NMR}: \delta_{\mathrm{H}}\left(400 \mathrm{MHz}, \mathrm{CD}_{2} \mathrm{Cl}_{2}\right) 7.01(2 \mathrm{H}$, $\left.\mathrm{d},{ }^{3} J=8.8, \mathrm{~N}-\mathrm{Ph} H-\mathrm{Ar}\right), 7.12-7.16(6 \mathrm{H}, \mathrm{m}, \mathrm{N}-\mathrm{Ph} H), 7.32(4 \mathrm{H}, \mathrm{t}$, $\left.{ }^{3} J=7.6, \mathrm{~N}-\mathrm{Ph} H\right), 7.40\left(4 \mathrm{H}, \mathrm{d},{ }^{3} J=8.8, \mathrm{~N}-\mathrm{Ph} H-\mathrm{Ar}\right), 7.60(2 \mathrm{H}, \mathrm{d}$, $\left.{ }^{3} J=8.4, \mathrm{Ph}-\mathrm{Ph} H-\mathrm{CN}\right), 7.65\left(4 \mathrm{H}, \mathrm{d},{ }^{3} J=8.4, \mathrm{Ph}-\mathrm{Ph} H-\mathrm{CN}\right)$. ${ }^{13} \mathrm{C}-\mathrm{NMR}: \delta_{\mathrm{C}} 87.6,94.7,111.5,114.8,119.1,121.9,124.5,125.9$, 129.0, 130.0, 132.3, 132.6, 133.2, 147.4, 149.3. HR-FT-MALDI-MS (DHB): calcd for $\mathrm{C}_{27} \mathrm{H}_{18} \mathrm{~N}_{2}\left(\mathrm{M}^{+}\right) 370.14645$ found 370.14592 .

Chromophore 1Q. Title compound was synthesized from 5 (114 mg) following the general method. Yellow solid. Yield (91 mg, 80\%). $R_{\mathrm{f}} 0.65\left(\mathrm{SiO}_{2}\right.$; EtOAc/hexane $\left.1: 4\right)$. Mp $232{ }^{\circ} \mathrm{C}$. IR (HATR) $\nu_{\max } / \mathrm{cm}^{-1} 2206$ (CN), 1585, 1485, 1269, 1110, 1021, 830. ${ }^{1} \mathrm{H}-\mathrm{NMR}: \delta_{\mathrm{H}}\left(500 \mathrm{MHz} ; \mathrm{CD}_{2} \mathrm{Cl}_{2}\right) 7.06\left(4 \mathrm{H}, \mathrm{d},{ }^{3} \mathrm{~J} 9.0, \mathrm{~N}-\mathrm{Ph} H-\mathrm{Ar}\right)$, 7.15-7.19 (3H, m, N-PhH), $7.34\left(3 \mathrm{H}, \mathrm{t},{ }^{3} J\right.$ 7.0, N-PhH), $7.43(4 \mathrm{H}$, $\left.\mathrm{d},{ }^{3} J=9.0, \mathrm{~N}-\mathrm{Ph} H-\mathrm{Ar}\right), 7.59\left(4 \mathrm{H}, \mathrm{d},{ }^{3} \mathrm{~J}=8.6, \mathrm{Ph}-\mathrm{Ph} H-\mathrm{CN}\right), 7.62$ $\left(4 \mathrm{H}, \mathrm{d},{ }^{3} J=8.6, \mathrm{Ph}-\mathrm{Ph} H-\mathrm{CN}\right) .{ }^{13} \mathrm{C}-\mathrm{NMR}: \delta_{\mathrm{C}}\left(125 \mathrm{MHz} ; \mathrm{CD}_{2} \mathrm{Cl}_{2}\right)$ 88.0, 94.3, 111.7, 116.14, 119.1, 123.6, 125.4, 126.6, 128.8, 130.2, 132.3, 132.6, 133.4, 146.8, 148.4. HR-FT-MALDI-MS (DHB): calculated for $\mathrm{C}_{36} \mathrm{H}_{21} \mathrm{~N}_{3}\left(\mathrm{M}^{+}\right) 495.17355$ found 495.17365.

\section{General method for the synthesis of $2 L$ and $2 Q$}

Iodinated triphenylamine derivatives $\mathbf{4}$ or $\mathbf{5}(0.34 \mathrm{mmol})$ and 2-(4-cyanophenyl)vinyl-boronic acid pinacol ester $(0.37$ or $0.75 \mathrm{mmol}$ ) were dissolved in dioxane/water (50 ml, $4: 1)$. Argon was bubbled through the mixture for $10 \mathrm{~min}$, whereupon $\mathrm{Na}_{2} \mathrm{CO}_{3}$ (127 mg, $1.20 \mathrm{mmol}$ ) and $\mathrm{PdCl}_{2}\left(\mathrm{PPh}_{3}\right)_{2}$ (24 mg, $0.034 \mathrm{mmol}$ ) were added and the mixture was heated to $90{ }^{\circ} \mathrm{C}$ for $8 \mathrm{~h}$. The reaction mixture was poured into sat. solution of $\mathrm{NH}_{4} \mathrm{Cl}(100 \mathrm{ml})$ and was extracted with DCM $(3 \times 100 \mathrm{ml})$. The combined organic extracts were dried over anhydrous $\mathrm{Na}_{2} \mathrm{SO}_{4}$ and concentrated in vacuo. The crude product was purified by column chromatography $\left(\mathrm{SiO}_{2}\right.$, EtOAc/hexane $\left.1: 4\right)$.

Chromophore $2 \mathbf{L}$. Title compound was synthesized from 4 (126 mg) following the general method. Yellow solid. Yield (119 mg, 94\%), $R_{\mathrm{f}} 0.5\left(\mathrm{SiO}_{2}\right.$; EtOAc/hexane $\left.1: 4\right)$. Mp $131{ }^{\circ} \mathrm{C}$. IR (HATR) $\nu_{\text {max }} / \mathrm{cm}^{-1} 2223$ (CN), 1583, 1484, 1276, 1168, 968, 824. ${ }^{1} \mathrm{H}-\mathrm{NMR}: \delta_{\mathrm{H}}\left(400 \mathrm{MHz}, \mathrm{CD}_{2} \mathrm{Cl}_{2}\right) 7.02\left(2 \mathrm{H}, \mathrm{d},{ }^{3} \mathrm{~J}=16.4, \mathrm{Ph}-\mathrm{C} H=\right.$
$\mathrm{CH}-\mathrm{PhCN}$ ), $7.08\left(4 \mathrm{H}, \mathrm{d},{ }^{3} J=8.8, \mathrm{~N}-\mathrm{Ph} H-\mathrm{CH}=\mathrm{CH}\right), 7.12-7.15$ $(3 \mathrm{H}, \mathrm{m}, \mathrm{N}-\mathrm{Ph} H), 7.17$ (2H, d, $\left.{ }^{3} J=16.4, \mathrm{Ph}-\mathrm{CH}=\mathrm{CH}-\mathrm{PhCN}\right)$, $7.31\left(3 \mathrm{H}, \mathrm{t},{ }^{3} J=7.0, \mathrm{~N}-\mathrm{Ph} H\right), 7.43\left(4 \mathrm{H}, \mathrm{d},{ }^{3} J=9.0, \mathrm{~N}-\mathrm{Ph} H-\mathrm{Ar}\right)$, $7.59\left(4 \mathrm{H}, \mathrm{d},{ }^{3} J=8.6\right.$, Ph-PhH-CN), $7.62\left(4 \mathrm{H}, \mathrm{d},{ }^{3} J=8.6\right.$, PhPhH-CN). ${ }^{13} \mathrm{C}-\mathrm{NMR}: \delta_{\mathrm{C}}\left(125 \mathrm{MHz}, \mathrm{CD}_{2} \mathrm{Cl}_{2}\right)$ 88.0, 94.3, 111.7, $116.14,119.1,123.6,125.4,126.6,128.8$, 130.2, 132.3, 132.6, 133.4, 146.8, 148.4. HR-MALDI-MS (DHB): calcd for $\mathrm{C}_{27} \mathrm{H}_{20} \mathrm{~N}_{2}$ $\left(\mathrm{M}^{+}\right) 372.16210$ found 372.16248 .

Chromophore 2Q. Title compound was synthesized from $\mathbf{5}$ (169 $\mathrm{mg}$ ) following the general method. Yellow solid. Yield (139 mg, 82\%). $R_{\mathrm{f}} 0.55$ ( $\mathrm{SiO}_{2}$; EtOAc/hexane $\left.1: 4\right) . \mathrm{Mp} 203{ }^{\circ} \mathrm{C}$. IR (HATR) $\nu_{\max } / \mathrm{cm}^{-1} 3180,221$ (CN), 1585, 1484, 1276, 1171, 958, 831. ${ }^{1} \mathrm{H}-\mathrm{NMR}: \delta_{\mathrm{H}}\left(400 \mathrm{MHz}, \mathrm{CD}_{2} \mathrm{Cl}_{2}\right) 7.02\left(2 \mathrm{H}, \mathrm{d},{ }^{3} \mathrm{~J}=16.4, \mathrm{Ph}-\right.$ $\mathrm{CH}=\mathrm{CH}-\mathrm{PhCN}), 7.08\left(4 \mathrm{H}, \mathrm{d},{ }^{3} \mathrm{~J}=8.8, \mathrm{~N}-\mathrm{Ph} H-\mathrm{CH}=\mathrm{CH}\right), 7.12-$ $7.15(3 \mathrm{H}, \mathrm{m}, \mathrm{N}-\mathrm{Ph} H), 7.17\left(2 \mathrm{H}, \mathrm{d},{ }^{3} \mathrm{~J}=16.4\right.$, $\mathrm{Ph}-\mathrm{CH}=\mathrm{CH}-$ PhCN), $7.31\left(3 \mathrm{H}, \mathrm{t},{ }^{3} J=7.0, \mathrm{~N}-\mathrm{Ph} H\right), 7.43\left(4 \mathrm{H}, \mathrm{d},{ }^{3} J=9.0, \mathrm{~N}-\right.$ $\mathrm{Ph} H-\mathrm{Ar}), 7.59$ (4H, d, $\left.{ }^{3} \mathrm{~J}=8.6, \mathrm{Ph}-\mathrm{Ph} H-\mathrm{CN}\right), 7.62\left(4 \mathrm{H}, \mathrm{d},{ }^{3} \mathrm{~J}=\right.$ 8.6, Ph-PhH-CN). ${ }^{13} \mathrm{C}-\mathrm{NMR}: \delta_{\mathrm{C}}\left(125 \mathrm{MHz}, \mathrm{CD}_{2} \mathrm{Cl}_{2}\right)$ 88.0, 94.3, $111.7,116.14,119.1,123.6,125.4,126.6,128.8,130.2,132.3$, 132.6, 133.4, 146.8, 148.4. HR-MALDI-MS (DHB): calcd for $\mathrm{C}_{36} \mathrm{H}_{25} \mathrm{~N}_{3}\left(\mathrm{M}^{+}\right) 499.20430$ found 499.20466.

\section{Acknowledgements}

This research was supported by the Czech Science Foundation (13-01061S). M. L. and F. B. are indebted to the Ministry of Education, Youth and Sports of the Czech Republic (LG13053).

\section{Notes and references}

1 A. Abbotto, L. Beverina, R. Bozio, S. Bradamante, C. Ferrante, G. A. Pagani and R. Signorini, Adv. Mater., 2000, 12, 1963.

2 F. Hao, X. Zhang, Y. Tian, H. Zhou, L. Li, J. Wu, S. Zhang, J. Yang, B. Jin, X. Tao, G. Zhou and M. Jiang, J. Mater. Chem., 2009, 19, 9163.

3 M. Grzybowski, E. Glodkowska-Mrowka, V. Hugues, W. Brutkowski, M. Blanchard-Desce and D. T. Gryko, Chem.-Eur. J., 2015, 21, 9101.

4 E. Baggaley, I. V. Sazanovich, J. A. Gareth Williams, J. W. Haycock, S. W. Botchway and J. A. Weinstein, RSC Adv., 2014, 4, 35003.

5 M. Kong, T. Wang, X. Tian, F. Wang, Y. Liu, Q. Zhang, H. Wang, H. Zhou, J. Wu and Y. Tian, J. Mater. Chem. C, 2015, 3, 5580 .

6 I. Fitilis, M. Fakis, J. Polyzos, V. Giannetas and P. Persephonis, J. Photochem. Photobiol., A, 2010, 215, 25.

7 M. Jin, J. Xie, J.-P. Malval, A. Spangenberg, O. Soppera, D.-L. Versace, T. Leclerc, H. Pan, D. Wan, H. Pu, P. Baldeck, O. Poizat and S. Knopf, J. Mater. Chem. C, 2014, 2, 7201.

8 J. Mačiulaitis, M. Deveikytè, S. Rekštytè, M. Bratchikov, A. Darinskas, A. Šimbelytė, G. Daunoras, A. Laurinavičienė, A. Laurinavičius, R. Gudas, M. Malinauskas and R. Mačiulaitis, Biofabrication, 2015, 7, 015015.

9 S. Kawata, H. B. Sun, T. Tanaka and K. Takada, Nature, 2001, 412, 697. 
10 Z. Li, J. Torgersen, A. Ajami, S. Mühleder, X. Qin, W. Husinsky, W. Holnthoner, A. Ovsianikov, J. Stampfl and R. Liska, RSC Adv., 2013, 3, 15939.

11 J.-L. Wu, B. Gu, N. Sheng, D. Liu and Y. Cui, Appl. Phys. Lett., 2014, 105, 171113.

12 C. Zheng, W. Chen, S. Cai, X. Xiao and X. Ye, Mater. Lett., 2014, 131, 284.

13 Z. Gan, Y. Cao, R. A. Evans and M. Gu, Nat. Commun., 2013, 4, 3061.

14 X. Zhou, Y. Hou and J. Lin, AIP Adv., 2015, 5, 030701.

15 F. Bureš, $R S C A d v$. , 2014, 4, 58826.

16 M. Pawlicki, H. A. Collins, R. G. Denning and H. L. Anderson, Angew. Chem., Int. Ed., 2009, 48, 3244.

17 F. Terenziani, C. Katan, E. Badaeva, S. Tretiak and M. Blanchard-Desce, Adv. Mater., 2008, 20, 4641.

18 Y. Wang, S. Yin, J. Liu, L. Yao, G. Wang, D. Liu, B. Jing, L. Cheng, H. Zhong, X. Shi, Q. Fang and S. Qian, RSC Adv., 2014, 4, 10960.

19 N. S. Makarov, S. Mukhopadhyay, K. Yesudas, J.-L. Brédas, J. W. Perry, A. Pron, M. Kivala and K. Müllen, J. Phys. Chem. A, 2012, 116, 3781.

20 L. Yan, X. Chen, Q. He, Y. Wang, X. Wang, Q. Guo, F. Bai, A. Xia, D. Aumiler, S. Vdović and S. H. Lin, J. Phys. Chem. A, 2012, 116, 8693.

21 P. Hrobarik, V. Hrobarikova, I. Sigmundova, P. Zahradnik, M. Fakis, I. Polyzos and P. Persephonis, J. Org. Chem., 2011, 76, 8726.

22 Y. M. Poronik, V. Hugues, M. Blanchard-Desce and D. T. Gryko, Chem.-Eur. J., 2012, 18, 9258.

23 F. Terenziani, C. Le Droumaguet, C. Katan, O. Mongin and M. Blanchard-Desce, ChemPhysChem, 2007, 8, 723.

24 C. Huang, M. M. Sartin, N. Siegel, M. Cozzuol, Y. Zhang, J. M. Hales, S. Barlow, J. W. Perry and S. R. Marder, J. Mater. Chem., 2011, 21, 16119.

25 Y. Wan, L. Yan, Z. Zhao, X. Ma, Q. Guo, M. Jia, P. Lu, G. Ramos-Ortiz, J. L. Maldonado, M. Rodríguez and A. Xia, J. Phys. Chem. B, 2010, 114, 11737.

26 F.-A. Martin, C. Baudequin, C. Fiol-Petit, M. Darabantu, Y. Ramondenc and N. Plé, Tetrahedron, 2014, 70, 2546.

27 H. Xiao, C. Mei, B. Li, N. Ding, Y. Zhang and T. Wei, Dyes Pigm., 2013, 99, 1051.

28 V. Parthasarathy, S. Fery-Forgues, E. Campioli, G. Recher, F. Terenziani and M. Blanchard-Desce, Small, 2011, 7, 3219.

29 H. M. Kim, M. S. Seo, S.-J. Jeon and B. R. Cho, Chem. Commun., 2009, 3219.

30 J. E. Rogers, J. E. Slagle, D. G. McLean, R. L. Sutherland, M. C. Brant, J. Heinrichs, R. Jakubiak, R. Kannan, L.-S. Tan and P. A. Fleitz, J. Phys. Chem. A, 2007, 111, 1899.

31 C. Katan, F. Terenziani, O. Mongin, M. H. V. Werts, L. Porrès, T. Pons, J. Mertz, S. Tretiak and M. Blanchard-Desce, J. Phys. Chem. A, 2005, 109, 3024.

32 C. Katan, S. Tretiak, M. H. V. Werts, A. J. Bain, R. J. Marsh, N. Leonczek, N. Nicolaou, E. Badaeva, O. Mongin and M. Blanchard-Desce, J. Phys. Chem. B, 2007, 111, 9468.

33 S.-J. Chung, T.-C. Lin, K.-S. Kim, G. S. He, J. Swiatkiewicz, P. N. Prasad, G. A. Baker and F. V. Bright, Chem. Mater., 2001, 13, 4071.
34 H. Y. Woo, B. Liu, B. Kohler, D. Korystov, A. Mikhailovsky and G. C. Bazan, J. Am. Chem. Soc., 2005, 127, 14721.

35 R. Orłowski, M. Banasiewicz, G. Clermont, F. Castet, R. Nazir, M. Blanchard-Desce and D. T. Gryko, Phys. Chem. Chem. Phys., 2015, 17, 23724.

36 I. Fitilis, M. Fakis, I. Polyzos, V. Giannetas, P. Persephonis and J. Mikroyannidis, J. Phys. Chem. A, 2008, 112, 4742.

37 D. Cvejn, E. Michail, I. Polyzos, N. Almonasy, O. Pytela, M. Klikar, T. Mikysek, V. Giannetas, M. Fakis and F. Burě̌, J. Mater. Chem. C, 2015, 3, 7345.

38 O. P. Varnavski, J. C. Ostrowski, L. Sukhomlinova, R. J. Twieg, G. C. Bazan and T. Goodson III, J. Am. Chem. Soc., 2002, 124, 1736.

39 M. S. Yosubov, E. N. Tveryakova, E. A. Krasnokutskaya, I. A. Perederyna and V. V. Zhdankin, Synth. Commun., 2007, 37, 1259.

40 A. A. Isse and A. Gennaro, J. Phys. Chem. B, 2010, 114, 7894. 41 J. Kulhánek, F. Bureš, O. Pytela, T. Mikysek, J. Ludvík and A. Růžička, Dyes Pigm., 2010, 85, 57.

42 A. S. Davidov, Theory of molecular excitons, Plenum Press, New York, 1971.

43 D. Beljonne, W. Wenseleers, E. Zojer, Z. Shuai, H. Vogel, S. J. K. Pond, J. W. Perry, S. R. Marder and J.-L. Brédas, Adv. Funct. Mater., 2002, 12, 631.

44 F. Terenziani, C. Sissa and A. Painelli, J. Phys. Chem. B, 2008, 112, 5079.

45 C. Liu, K.-C. Tang, H. Zhang, H.-A. Pan, J. Hua, B. Li and P.-T. Chou, J. Phys. Chem. A, 2012, 116, 12339.

46 E. Lippert, Z. Naturforsch., A: Astrophys., Phys. Phys. Chem., 1955, 10, 541.

47 N. Mataga, Y. Kaifu and M. Koizumi, Bull. Chem. Soc. Jpn., 1955, 28, 690.

48 I. Fitilis, M. Fakis, I. Polyzos, V. Giannetas, P. Persephonis, P. Vellis and J. Mikroyannidis, Chem. Phys. Lett., 2007, 447, 300.

49 C.-K. Wang, K. Zhao, Y. Su, Y. Ren, X. Zhao and Y. Luo, J. Chem. Phys., 2003, 119, 1208.

50 Y. Luo, P. Norman, P. Macak and H. Ågren, J. Phys. Chem. A, 2000, 104, 4718.

51 M. Drobizhev, A. Karotki, Y. Dzenis, A. Rebane, Z. Suo and C. W. Spangler, J. Phys. Chem. B, 2003, 107, 7540.

52 J. Yoo, S. K. Yang, M.-Y. Jeong, H. C. Ahn, S.-J. Jeon and B. R. Cho, Org. Lett., 2003, 5, 645.

53 A. Abbotto, L. Beverina, R. Bozio, A. Facchetti, C. Ferrante, G. A. Pagani, D. Pedron and R. Signorini, Chem. Commun., 2003, 2144.

54 M. Rumi, S. J. K. Pond, T. M. Friedrichsen, Q. Zhang, M. Bishop, Y. Zhang, S. Barlow, S. R. Marder and J. W. Perry, J. Phys. Chem. C, 2008, 112, 8061.

55 M. J. Frisch, G. W. Trucks, H. B. Schlegel, G. E. Scuseria, M. A. Robb, J. R. Cheeseman, G. Scalmani, V. Barone, B. Mennucci, G. A. Petersson, H. Nakatsuji, M. Caricato, X. Li, H. P. Hratchian, A. F. Izmaylov, J. Bloino, G. Zheng, J. L. Sonnenberg, M. Hada, M. Ehara, K. Toyota, R. Fukuda, J. Hasegawa, M. Ishida, T. Nakajima, Y. Honda, O. Kitao, H. Nakai, T. Vreven, J. A. Montgomery Jr, J. E. Peralta, F. Ogliaro, M. Bearpark, J. J. Heyd, 
E. Brothers, K. N. Kudin, V. N. Staroverov, T. Keith, R. Kobayashi, J. Normand, K. Raghavachari, A. Rendell, J. C. Burant, S. S. Iyengar, J. Tomasi, M. Cossi, N. Rega, J. M. Millam, M. Klene, J. E. Knox, J. B. Cross, V. Bakken, C. Adamo, J. Jaramillo, R. Gomperts, R. E. Stratmann, O. Yazyev, A. J. Austin, R. Cammi, C. Pomelli, J. W. Ochterski, R. L. Martin, K. Morokuma, V. G. Zakrzewski, G. A. Voth, P. Salvador, J. J. Dannenberg, S. Dapprich, A. D. Daniels, O. Farkas, J. B. Foresman, J. V. Ortiz, J. Cioslowski and D. J. Fox, Gaussian 09, Revision D.01, Gaussian, Inc., Wallingford CT, 2013.

56 M. A. Thompson, ArgusLab 4.0, Planaria Software LLC, Seattle, WA, http://www.arguslab.com.
57 D. F. Eaton, Pure Appl. Chem., 1988, 60, 1107.

58 G. Jones II and M. A. Rahman, J. Phys. Chem., 1994, 98, 13028.

59 N. S. Makarov, M. Drobizhe and A. Rebane, Opt. Express, 2008, 16, 4029.

60 B. Liu, Q. Zhang, H. Ding, G. Hu, Y. Du, C. Wang, J. Wu, S. Li, H. Zhou, J. Yang and Y. Tian, Dyes Pigm., 2012, 95, 149.

61 B. Jędrzejewska, M. Gordel, J. Szeremeta, P. Krawczyk and M. Samoć, J. Org. Chem., 2015, 80, 9641.

62 M. J. Piao, K. Chajara, S. Y. Yoon, H. M. Kim, S.-J. Jeon, T.-H. Kim, K. Song, I. Asselberghs, A. Persoons, K. Clays and B. R. Cho, J. Mater. Chem., 2006, 16, 2273. 